Documentación de las Ciencias de la Información ISSN: 0210-4210

http://dx.doi.org/10.5209/DCIN.61589

\title{
Difusión del patrimonio audiovisual de televisión en redes: perfiles oficiales en Twitter
}

\author{
Elena de la Cuadra Colmenares ${ }^{1} ; \mathrm{M}^{\mathrm{a}}$ Victoria Nuño Moral $^{2}$
}

Enviado: 25 de septiembre de 2018 / Aceptado: 4 de noviembre de 2018

Resumen. Este estudio se centrará en el papel de Twitter como garante del patrimonio audiovisual de la televisión pública española. Algo que, en principio, no es una de las funciones de una red social (o microblog), pero que es interesante analizar por las futuras utilidades que puede tener como salvaguardia de nuestro patrimonio televisivo.

Para acometer este estudio se realizará una búsqueda en las cuentas oficiales de cadenas y programas del ente público, y se estudiará cada una de ellas con una ficha de análisis mediante la cual podremos determinar el uso de fragmentos audiovisuales y su posterior recuperación.

Palabras clave: Redes sociales; Twitter; Patrimonio Audiovisual; Televisión; RTVE

\section{[en] Dissemination of the audiovisual heritage of television in networks: official profiles on Twitter}

\begin{abstract}
This study will focus on the role of Twitter as a guarantor of the audiovisual heritage of the Spanish public television. Something that, in principle, is not one of the functions of a social network (or microblog), but it is interesting to analyze for future benefits it can have as a safeguard of our television heritage.

To undertake this study, a search will be carried out on the official accounts of the chainnels and programs of the Spanish public television, and each of them will be studied with an analysis sheet through which we can determine the use of audiovisual fragments and their subsequent recovery.
\end{abstract}

Keywords: Social netwoks; Twitter; Audiovisual heritage; Television; RTVE

Sumario: Introducción. Redes sociales: Twitter como medio de comunicación. Objeto y metodología. Muestra. Parámetros de análisis. Tipología de vídeos tuiteados. Resultados por perfiles. Bibliografía.

Cómo citar. Cuadra Colmenares, E.; Nuño Moral, $M^{a} V$. (2018) Difusión del patrimonio audiovisual de televisión en redes: perfiles oficiales en Twitter en Documentación de las Ciencias de la Información 41, 101-121.

\footnotetext{
$1 \quad$ Universidad Complutense de Madrid ecuadra@ucm.es

$2 \quad$ Universidad de Extremadura mvnunmor@unex.es
} 


\section{Introducción}

El material audiovisual se postula como uno de los grandes baluartes testimoniales de nuestra sociedad. Uno de los principales objetivos que han de tener los diferentes agentes que integran la denominada sociedad de la información, es ser conscientes del valor patrimonial que tiene el material audiovisual como parte inherente al patrimonio cultural de un país. En este contexto, el papel que juegan los medios de comunicación es crucial.

Y lo decimos no sólo por las actividades que hasta este momento se han realizado especialmente desde una perspectiva económica, tales como la reposición de programas o la producción de los mismos a partir del material de archivo conservado por las diferentes entidades. Sino también por el papel que en este sentido está jugando la relación entre dichos medios y la aparición de las redes sociales, lo cual está provocando un cambio de escenario y contexto en el panorama informativo. Este fenómeno ha sido acuñado por muchos autores como convergencia. A este respecto Hidalgo (2013:54) señala que, a pesar de que las imágenes que emitían las cadenas de televisión reflejaban la vida cotidiana y confirmarían la memoria histórica de un país, los archivos audiovisuales tienen un carácter eminentemente empresarial destinado a facilitar la producción y emisión de programas.

Ello ha motivado -ya se originó con la introducción de la digitalización en el ámbito informativo y como consecuencia en el documental-, que el material audiovisual deje de ser algo exclusivo del medio y que dicho patrimonio se ponga en valor y resulte útil para cualquier generación venidera y le ayude a comprender la realidad actual. Esta idea la exponen Fernández-Quijada y Fortino (2009: 546) al indicar que: "la accesibilidad en línea constituye una condición indispensable para optimizar los beneficios que pueden extraer de estos contenidos los ciudadanos y los colectivos sociales".

Tal y como manifiesta Edmonson (2018:8), la práctica audiovisual "se ha vuelto ampliamente reconocida entre las instituciones dedicadas a la preservación del patrimonio, las industrias audiovisuales y de la información, y en la academia, donde es ahora el centro de varios programas de licenciatura y maestría en el mundo". Además, en el terreno informativo debe prevalecer la protección de lo efímero en cuanto a información de actualidad se refiere. Para hacer frente a esta situación, la UNESCO ha propiciado y respaldado muchas acciones conjuntas entre las que destacan dos, en pro del material audiovisual. Son lo que conocemos como Programa Memoria del Mundo ${ }^{3}$ (1992) y el Día Mundial del Patrimonio Audiovisual (2005).

\section{Redes sociales: Twitter como medio de comunicación}

En 2014, la UNESCO empieza a tomar conciencia del papel que juegan las redes sociales en este entorno audiovisual. Así lo demuestra la Directora General de la UNESCO , Irina Bokova ${ }^{4}$, con motivo de la celebración del Día Mundial del Patrimonio Audiovisual, cuando señala que en ese momento ya "se están registrando cambios monumentales que transforman el modo en que se generan y gestionan la

https://en.unesco.org/programme/mow

http://www.un.org/es/events/audiovisualday/2014/bokova_message.shtml 
información y los recursos y la forma en que se accede a ellos, y cuando está surgiendo una cantidad cada vez mayor de material audiovisual en formato digital (correos electrónicos, blogs, redes sociales y sitios web), todo el patrimonio audiovisual está en peligro. Millones de películas, grabaciones sonoras y en vídeo y discos corren el riesgo de convertirse en polvo, borrarse y desaparecer".

La llegada de las redes sociales ha motivado que todos los medios, nativos o no en el ámbito digital, saquen provecho en su actividad informativa. Jenkins (2008: 15) alude a un cambio cultural donde el usuario se va a ver incentivado en la búsqueda de nuevas informaciones y donde va a poder ser capaz de conectar diferentes tipos de contenidos. Este mismo autor señala que: "si la revolución digital presagiaba que los nuevos medias desplazarían a los viejos, el emergente paradigma de la convergencia asume que los viejos y nuevos medios interaccionarán de formas cada vez más complejas" (Jenkins, 2008: 17).

Este trabajo no tiene por objeto estudiar el uso de dichos medios desde el punto de vista de la audiencia sino reflexionar sobre si dichos medios manejan y son portadores de lo que denominamos patrimonio audiovisual ${ }^{5}$. Tal y como expone Pérez Sánchez (2018:105): "las redes sociales, lejos de ser un peligro para el medio televisivo lineal, colaboran muchas veces en el éxito del propio medio, siendo beneficiadas ambas ventanas por las posibilidades que se ofrecen mutuamente". A este respecto, Gallego, F. (2013:14) explica que: "los contenidos que se ofrecen en televisión y la información que fluye por los social media se retroalimentan: la inmensa mayoría de las conversaciones que se registran hoy en redes sociales son conversaciones en las cuales los medios tradicionales, por mucho que pese a algunos analistas e investigadores, son sus suministradores centrales y la televisión, a su vez, utiliza la inmediatez y la tensión que los medios sociales desprenden para elaborar sus contenidos".

Twitter se ha convertido en un instrumento de trabajo que posibilita un mayor feedback entre periodistas y usuarios, tejiendo una red de comunicaciones tanto personales como institucionales. En este sentido, Vinader y Cuadra (2012:914) revelan que: "...la cantidad de información autorizada y veraz que circula en las redes es apabullante: suficiente para tener los datos al minuto y de la mejor fuente posible. Así, aunque la característica principal de las redes 2.0, como vimos al principio, es que se enriquecen con las aportaciones de todos los usuarios, queremos, con estas líneas, llamar la atención sobre la vuelta a las fuentes autorizadas, esta vez camufladas entre todo tipo de usuarios".

Cerviño Queiroz (2013:42) señala que: "los medios sociales en general desencadenan un proceso de utilización de la web 2.0 como una herramienta para nutrir los periodistas de las organizaciones comunicacionales con contenidos complementarios a los reunidos por los métodos tradicionales. Este sistema se retroalimenta porque en la medida que el reportero sigue a los usuarios adecuados, irá aumentado el número de usuarios que seguirán al reportero". Esta relación medio-espectador también la recoge Gallego (2013:15) en relación a Twitter. Explica que la vinculación de esta red con "el sector de la televisión se debe a que su uso está ya normalizado en el momento de la emisión en directo, ya sea como feedback puntual de los responsables de la cadena o del programa televisivo o como ejercicio táctico organizado

En la tesis doctoral defendida en 2016, la doctora Paloma Hidalgo repasa las definiciones que los diferentes especialistas vierten sobre patrimonio audiovisual y lo liga al concepto de patrimonio audiovisual de televisión. 
para captar y fidelizar a los espectadores... [Twitter] permite servir como canal de comunicación, complementario y paralelo, de otros medios más masivos entre los que destaca la centralidad de la televisión, que no del televisor. Twitter es un electrocardiograma de la sociedad y, dentro de ella, es una plataforma que toma bien el pulso a lo estrictamente televisivo".

Twitter se ha convertido en uno de los fenómenos más estudiados tanto dentro de la literatura académica como fuera de ella en lo que a redes sociales se refiere. De ello emana una discusión en torno a su clasificación como medio social o medio de comunicación. Beatriz Cerviño (2013:79) aboga por la segunda opción ya que, tal y como indica la autora, su investigación ha confirmado el uso de las redes sociales en las rutinas informativas. En concreto, el uso de Twitter en más del 80\% de las tareas periodísticas provoca que "la función de Twitter en la difusión de la información quizás sea su principal razón de éxito, puesto que su función de relación social es mínima si comparada a su importancia como news media".

Este proceso de convergencia de recursos y contenidos es detallado por González Molina y Ramos del Cano (2014:38) como una "transformación que se puede abordar desde la aceleración en la circulación de noticias, el aumento del número de actores participantes en la producción de informaciones y el cambio en la relación que se establece entre medios y público”. Por su parte, Salaverría y García Avilés (2008:32) aluden a la convergencia en el lenguaje y a su origen en los medios digitales cuando señalan que: "los propios lenguajes periodísticos son ejemplo de convergencia: los contenidos multimedia que hoy caracterizan a las formas más vanguardistas del periodismo son, en el fondo, una amalgama de los lenguajes explorados durante el siglo XX por los medios impresos y audiovisuales".

Las redes sociales, por tanto, se han convertido en una herramienta esencial para la práctica periodística actual. Tal y como apunta López Meri (2015:35): "las implicaciones de Twitter en el periodismo son palpables en todos los estadios del proceso comunicativo, tanto en la producción, como en la difusión y el consumo de contenidos informativos". Pero Twitter no es sólo importante como apoyo a la labor informativa, especialmente a su función como fuente de información. Hoy ya es algo más; tal y como anota Noguera Vivo (2011:94): "Twitter convierte a las fuentes en medios. (...) No se necesitan mediadores o filtros (medios de comunicación) para trasladar un mensaje y que este llegue cuanto antes a la audiencia".

Dichas características propias del periodismo en el ámbito digital también son palpables en Twitter; y este hecho motiva que se pueda considerar como un medio de comunicación más. Martínez Gutiérrez (2014: 96) alude al periodismo de medios sociales que lo define como: "los modos y fórmulas de ejercer el periodismo mediante el uso de nuevos medios y su divulgación en redes sociales como se produce en Facebook y en Twitter". Y añade que este tipo de periodismo puede ayudar a impulsar nuevos medios de comunicación digitales "constituidos por redacciones y plantillas de periodistas jóvenes que ejercen el periodismo en Internet, no sólo por el prestigio de la cabecera de su propio medio, sino también por las redes sociales y por su credibilidad como marca personal" (Martínez Gutiérrez, 2014: 166).

Siguiendo la idea vertida por García Estévez (2018:56), en el terreno periodístico la obtención del material audiovisual (al que podríamos sumar el fotográfico, sonoro, etc.) con el que contextualizar la información periodística, infiere un mayor valor al documento informativo. Como ejemplifican muchos otros autores, las redes sociales en general y Twitter en particular ha alcanzado la unicidad como fuente de 
información, canal informativo y difusor de hechos noticiosos. Egea Bas (2016:59) ahonda en esta misma idea al afirmar que "la gran cantidad de datos que se genera diariamente en las redes las convierte en verdaderas abastecedoras de información, convirtiéndose en verdaderos canales de información".

A tenor de lo expuesto se puede concluir que Twitter irrumpe en el ámbito comunicativo, adoptando sus propias estructuras narrativas que junto con la impronta digital le convierte en uno de los medios de comunicación más usados por el público en general (hoy ya se ha acuñado el término de periodismo ciudadano unida a esta práctica periodística), por las empresas de comunicación y por los periodistas que las integran.

\section{Objeto y metodología}

El objeto de este estudio se centra en Twitter; en concreto, en los perfiles oficiales de Radio Televisión Española. El objetivo principal es analizar las cuentas oficiales de RTVE (cadenas o programas) susceptibles de publicar fragmentos de vídeo, estudiar los contenidos audiovisuales de esas publicaciones (tuits ${ }^{6}$ ) y determinar qué tipo de contenidos publican, en lo que hemos denominado "formatos", estableciendo cuáles son mayoritarios en cada perfil. Como objetivo secundario, queremos calibrar el potencial de Twitter como agente que garantice la conservación y difusión de patrimonio audiovisual español.

Se han analizado únicamente los perfiles verificados, aquellos que aparecen con el símbolo azul de cuenta oficial. Dicho símbolo sirve para "confirmar la autenticidad de las cuentas de interés público". Por su parte, se han descartado los perfiles -aun siendo oficiales-, pertenecientes a los trabajadores de cada cadena o programa, y los perfiles de programas sin verificación.

Tras elaborar esta lista con los perfiles oficiales, se ha procedido a agruparlos en cuatro bloques que detallamos en la tabla 1:

- Corporativos: los que publican información de la cadena en general, o de un canal determinado.

- Informativos: cuando pertenecen a algún programa de informativos, sean diarios o no diarios.

- Programas: programas de la cadena, sin atender a más criterios que la diferenciación entre programas, informativos y ficción.

- Series: ficción serializada.

\begin{tabular}{|l|l|}
\hline Informativos & Cuentas \\
\hline Telediarios & $@$ telediario_tve \\
\hline Repor TVE $(\mathrm{La} 1)$ & $@$ reportve \\
\hline Los desayunos & $@$ Desayunos_tve \\
\hline La Mañana & $@$ LaMananaTVE \\
\hline 2punto4 & $@$ 2punto4tve \\
\hline
\end{tabular}

Tal y como recomienda la Real Academia Española, se han adaptado las palabras referidas al uso de Twitter a su grafía en español; así, utilizaremos en estas líneas tuit, retuiteo, o tuiteros. Recomendación recogida por Fundéu en: https://www.fundeu.es/consulta/twitter-2260/ 


\begin{tabular}{|c|c|}
\hline La 2 Noticias & @La2noticias_tve \\
\hline El debate de La1 & (a)debatedela1_tve \\
\hline Programas & Cuentas \\
\hline Cachitos de hierro y cromo & @ cachitos_tve \\
\hline Cámara abierta 2.0 & @)camaraabierta \\
\hline Órbita Laika & @orbitalaika_tve \\
\hline Hora punta & @HoraPuntaTVE \\
\hline Aquí hay trabajo & @,AQHT_TVE \\
\hline Trabajo temporal & @)trabajotemp_tve \\
\hline Zoom Net & @ZzoomNet_tve \\
\hline Desaparecidos & @DSP_tve \\
\hline El gran reto musical & @GranRetoTVE \\
\hline Insuperables & @InsuperablesTVE \\
\hline Aquí la tierra & (a)aquilatierratve \\
\hline Pueblo de Dios & @PueblodeDiostve \\
\hline Maestros de la costura & @MaestrosCostura \\
\hline Mira quién baila & @Baila_TVE \\
\hline Atención, obras & @atencionobras \\
\hline El cazador de cerebros & (a)cazadorcerebros \\
\hline El pueblo más divertido & @pueblodivertido \\
\hline Masterchef & @masterchef \\
\hline Días de cine & $@$ DiasDeCine \\
\hline Torres en la cocina & @ torrescocinatve \\
\hline Corporativos & Cuentas \\
\hline TVE & @tve_tve \\
\hline La 1 & @La1_tve \\
\hline La 2 & @1a2_tve \\
\hline Clan & @ clan_tve \\
\hline 24 Horas & @ 24 h_tve \\
\hline Eurovisión & @eurovision_tve \\
\hline El Tiempo & @eltiempo_tve \\
\hline Archivo RTVE & @,ArchivoRTVE \\
\hline Playz & $@$ playz \\
\hline RTVE & $@$ rtve \\
\hline Teledeporte & @ teledeporte \\
\hline Series & Cuentas \\
\hline Cuéntame cómo pasó & $@$ cuentametve \\
\hline El ministerio del tiempo & @MdT_TVE \\
\hline
\end{tabular}




\begin{tabular}{|l|l|}
\hline Acacias 38 & $@$ acacias38_tve \\
\hline El caso & @elcaso_tve \\
\hline Servir y proteger & @SyP_tve \\
\hline La otra mirada & @laotramiradatve \\
\hline
\end{tabular}

Tabla 1. Perfiles que constituyen la muestra analizada

\section{Muestra}

La obtención de la muestra se obtuvo de los mensajes publicados a los largo del mes de agosto de 2018, en horarios de mañana, tarde y noche. De cada uno de los días seleccionados se estudian todos los tuits, prestando especial atención a los tuits originales que contengan un fragmento de vídeo.

Parámetros de análisis

Para realizar el estudio se procede a un análisis de los últimos 50 tuits de cada perfil. En este examen se tendrán en cuenta los siguientes ítems:

- Cuántos de esos 50 tuits contienen vídeos. Solo serán objeto de análisis los vídeos que se puedan activar dentro del propio tuit; no se tendrán en cuenta los enlaces a páginas web ni los enlaces a otro tipo de material online (Figura 1): solamente se considerarán tuits con vídeo los que contengan este material audiovisual en la misma publicación (Figura 2).

- Cuántos de esos 50 vídeos son retuiteados. Se considera relevante para este estudio saber si los perfiles publican información primaria de la propia cadena o programa, o si son publicaciones de otros perfiles de los que se hacen eco. Solo se tendrán en cuenta para este estudio los tuits propios.

- Una vez se ha determinado cuántos tuits son originales del perfil oficial, se examina la tipología de estos vídeos, la cual se especifica más abajo.

- Duración media de los tuits de cada perfil. Las propias características del medio (Twitter) hacen que los vídeos no sean muy extensos, por lo que se pretende corroborar esta afirmación con las mediciones de cada uno de los clips publicados.

\section{F. López@eucode - 18 ago. \\ Beurovision_tive Eplayz jHaced promo o algo, venga, que es hoyl

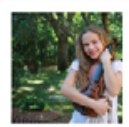 \\ icacion O MRTVE COM \\ 13 Arranca el Festival de Jóvenes Músicos 2018 de Edimburgo, con Sara Valencia como representante de (i)rtve $\partial^{\circ}$ La joven violinista es una de las ganadoras del talent musical de La 2 @ClasicosyReve \\ ○

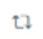 \\ ○ 9}

Tuit con enlace a otros formatos o sitios online Fuente: @playz

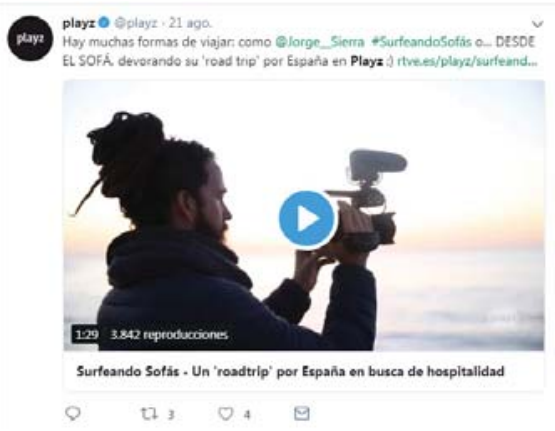

Figura 2

Tuit con vídeo insertado

Fuente:@playz 


\section{Tipología de vídeos tuiteados}

Para establecer una tipología de vídeos publicados en Twitter hemos partido de las denominaciones habituales en la narrativa televisiva (titulares, cabecera, promo,...), y hemos añadido algunos propios de Twitter.

- Avance programa: breve vídeo en el que se anuncia el contenido de un programa que se emitirá próximamente.

- Brutos: imágenes sin editar.

- Cabecera: producto audiovisual ligado a la serie que se repite idéntico en cada temporada o en toda la serie, en el que, con un rápido montaje de diferentes episodios, se presenta a los actores/personajes de la obra.

- Cabecera y primeros segundos

- Créditos finales: últimos segundos de un episodio en el que, mientras los títulos de crédito muestran a los componentes del equipo técnico, aparecen imágenes de lo que sucederá en el siguiente episodio.

- Fragmento: una parte de un programa o pieza más extenso. Puede ser "fragmento entrevista" o de otro tipo.

- Making of: vídeo en el que se ve al equipo en el proceso de rodaje.

- Momento destacado: muy similar a "fragmento", pero se refiere a fragmentos especialmente interesantes.

- Noticia: cuando se tuitea un fragmento de un Telediario con una noticia en concreto. En el caso de que sea de algún programa no informativo se añade un calificativo, por ejemplo, "noticia sociedad".

- Predicción: cuando es un fragmento o la totalidad de la predicción meteorológica.

- Primeros segundos.

- Promo: similar al tráiler, pero con un programa o serie de la cadena.

- Publicidad: vídeos para el lanzamiento de algún producto de la cadena. No es igual a "promo" porque puede ser que el producto no se emita, sino que sea algún objeto que se vende físicamente en comercios (DVD o revistas, por ejemplo).

- Titulares: primeros segundos de un telediario en el que se resumen las noticias que se van a tratar.

- Tráiler: producto cinematográfico y publicitario en el que se anuncia una película que se estrenará próximamente, mediante el montaje de algunos fragmentos del film.

- Vídeo doméstico: vídeo realizado con un móvil, generalmente por algún miembro del equipo, de manera espontánea para transmitir algún mensaje divertido o amable.

- Clips propios del lenguaje de Twitter, y propios de algunos de los perfiles (por ejemplo, @playz):

- After movie: montaje rápido de lo mejor de un acontecimiento una vez que este ha terminado.

- Cuestionario de verano: clip con una rápida sucesión de respuestas de un entrevistado, sin preguntas, a un ritmo muy rápido.

- Frase: vídeo extremadamente breve en el que apenas se recoge una frase de un personaje.

- Montaje de video. 
- Receta o resumen receta: vídeo en el que se explican los pasos de una receta sencilla, con un montaje muy rápido, e incluso, en ocasiones, con la cámara acelerada.

- Videoclip: al igual que en la industria discográfica, canciones acompañadas de un montaje de imágenes en movimiento.

\section{Resultados por perfiles}

A continuación, se presentan los resultados obtenidos por cada uno de los perfiles. Por un lado, se muestra una tabla resumen con los datos referentes al porcentaje de: a) tuits originales (publicados por el propio perfil) con vídeo; b) las publicaciones con vídeo retuiteados y c) la duración media de los vídeos originales. Por otro, se han elaborado gráficos en los que se refleja la tipología de formatos localizada en cada uno de los perfiles.

\section{Informativos}

La tabla 2 recoge el porcentaje de documentos audiovisuales que se han localizado en la muestra seleccionada, así como la media temporal relativa al conjunto de tuits con vídeo.

\begin{tabular}{|l|l|l|l|l|}
\hline Perfil Informativo & Cuentas & $\begin{array}{l}\text { Tuits con } \\
\text { videos (\%) }\end{array}$ & $\begin{array}{l}\text { Videos retui- } \\
\text { teados (\%) }\end{array}$ & $\begin{array}{l}\text { Duración } \\
\text { media (Tuits) }\end{array}$ \\
\hline Telediarios & @ telediario_tve & 72 & 8 & $01: 35$ \\
\hline Repor TVE (La 1) & @reportve & - & 4 & - \\
\hline Los desayunos & @Desayunos_tve & 50 & 6 & $01: 53$ \\
\hline La Mañana & @LaMananaTVE & - & 20 & - \\
\hline 2punto4 & @2punto4tve & 24 & 8 & $01: 27$ \\
\hline La 2 Noticias & @La2noticias_tve & 43,3 & - & $02: 47$ \\
\hline El debate de La1 & @debatedela1_tve & - & 24 & - \\
\hline
\end{tabular}

Tabla 2.Datos porcentuales y duración media del perfil Informativos

El perfil informativo Telediarios (@telediario_tve) recoge todas las ediciones de los informativos de TVE. Se ha hallado un total de 108 tuits con video, lo que supone un $72 \%$ del total. Toda la muestra comprende el periodo destinado al análisis, en concreto del 9 al 20 de agosto. Tal y como refleja el gráfico 1, sólo aparecen dos tipos de formatos: noticias y titulares, siendo mayor el porcentaje en el primer grupo. 


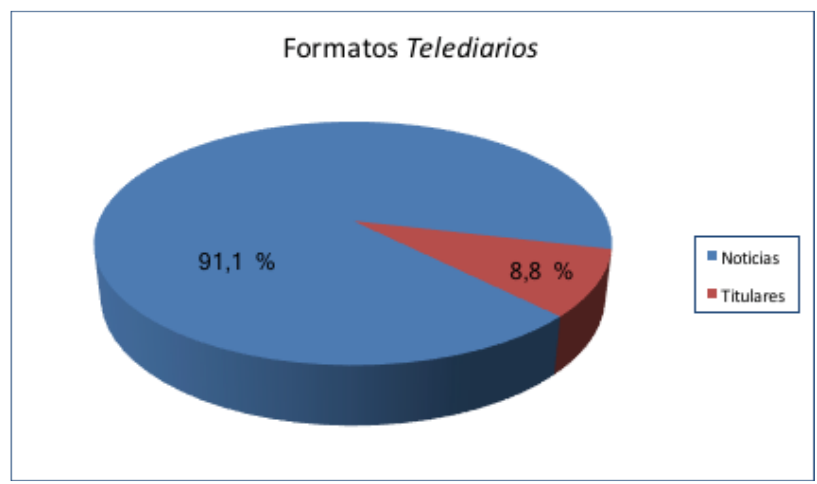

Gráfico 1. Promedio de vídeos por formatos de Telediarios (@telediario_tve)

En cuanto a la duración, la media se sitúa en torno al 1'35'". Es decir, en el caso de este perfil se mantienen los tiempos del contexto tradicional. Como cabría esperar, la duración media de los sumarios es superior al formato noticias, situándose en algo más de $4^{\prime} 30^{\prime \prime}$.

El programaLos Desayunos (@Desayunos_tve) paraliza su actividad en la red social durante el periodo estival. Por este motivo, los documentos audiovisuales localizados se remontan al mes de julio. En total, se ha encontrado un $50 \%$ de tuits con videos propios. Por su parte, el número de formatos que aparece es superior (grafico 2), situándose en primer lugar los fragmentos de entrevista con un 76\%.

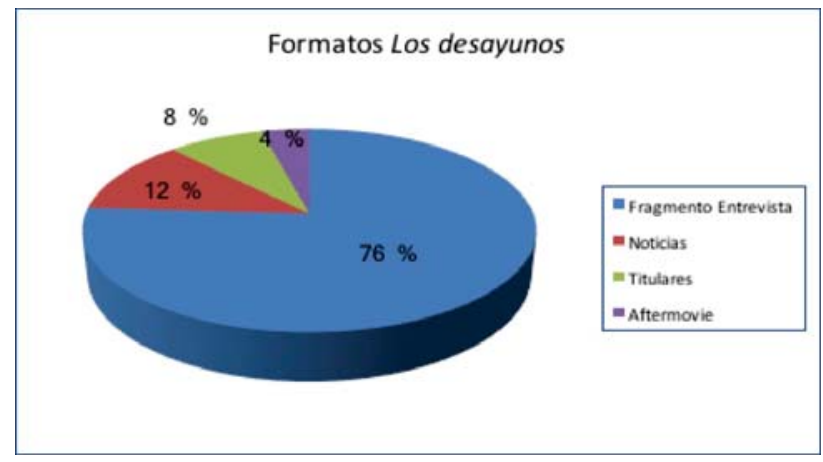

Gráfico 2. Promedio de vídeos por formatos de Los Desayunos (@Desayunos_tve)

La duración media respecto del total de tuits con videos localizados se sitúa en 1'53' . Tal y como está planificado el programa, la entrevista es el formato que más aparece con una media de 1'39'". Cabe destacar que el usuario podrá acceder a través de Twitter a lo más relevante de las entrevistas realizadas en cada uno de los programas ya que, en la mayoría de las ocasiones, aparecen desglosadas en varios tuis.

En el informativo juvenil 2.4 (@2punto4tve), se han localizado un total de 16 vídeos, de los cuales 12 son tuits con vídeo (24\%); los otros 4 restantes suponen sólo el 8\% de la muestra cuya procedencia reside en@24h_tve,@deporte_rtve y@telediario_tve. El gráfico 3 nos muestra nuevos formatos; junto a las noticias y titulares se han registrado montajes, avance de próximos programas y promos. 


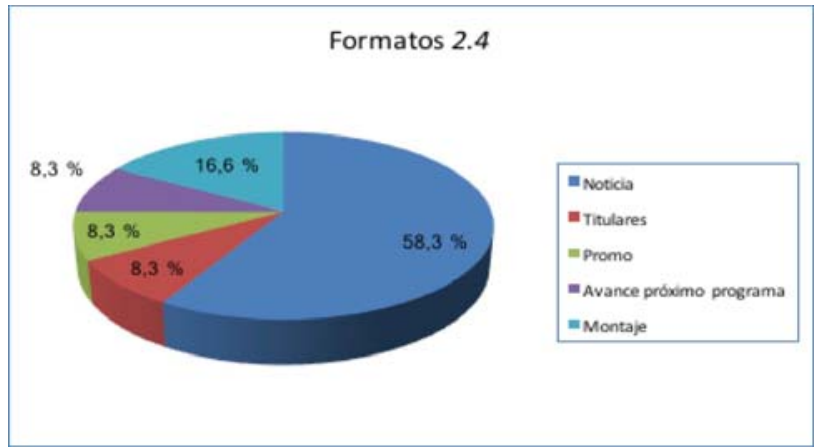

Gráfico 3. Promedio de vídeos por formatos de 2.4 (@2punto4tve)

Por su parte, en el caso del Informativo de la segunda cadena de TVE (@La2noticias_tve), la muestra ha registrado un total de 65 vídeos, todos tuits propios, que abarcan prácticamente un mes de tiempo: del 20 julio hasta el 22 de agosto. En el caso de este perfil destaca el hecho de que todos sus tuits tienen formato de noticia a excepción del video correspondiente a un montaje preparado ad hoc a modo de despedida de la presentadora de este Informativo Mara Torres, en el que aparece un recorrido de sus diez años al frente de dicho programa. La idiosincrasia de este programa hace que se diferencie de otros Informativos en el tratamiento periodístico de los acontecimientos así como de los temas que se tratan. Esto conlleva una duración superior de cada pieza informativa, si lo comparamos con otros programas similares, fruto de la impronta e identidad de la emisión.

Por último, los tres perfiles restantes (@reportve,@LaMananaTVE y@debatedela1_tve) se caracterizan porque carecen de tuis propios con videos. En el caso de Repor TVE y El Debate de la 1, existe una falta de actividad informativa.

\section{Programas}

La tabla 3 revela el porcentaje de tuits con video, su duración media y aquellos vídeos que han sido retuiteados de otras cuentas.

\begin{tabular}{|l|l|l|l|l|}
\hline Perfil Programas & Cuentas & $\begin{array}{l}\text { Tuits con } \\
\text { videos (\%) }\end{array}$ & $\begin{array}{l}\text { Videos } \\
\text { retuitea- } \\
\text { dos (\%) }\end{array}$ & $\begin{array}{l}\text { Duración } \\
\text { media } \\
\text { (Tuits) }\end{array}$ \\
\hline $\begin{array}{l}\text { Cachitos de hierro } \\
\text { y cromo }\end{array}$ & @cachitos_tve & 3,3 & 4,6 & $00: 19$ \\
\hline Cámara abierta 2.0 & @camaraabierta & 22 & 10 & $00: 54$ \\
\hline Órbita Laika & @orbitalaika_tve & - & - & - \\
\hline Hora punta & @HoraPuntaTVE & 34 & - & $02: 17$ \\
\hline Aquí hay trabajo & @AQHT_TVE & - & - & - \\
\hline Trabajo temporal & @trabajotemp_tve & 6 & - & $00: 24$ \\
\hline Zoom Net & @ZZoomNet_tve & 14 & - & $00: 59$ \\
\hline
\end{tabular}




\begin{tabular}{|l|l|l|l|l|}
\hline Desaparecidos & @DSP_tve & - & - & - \\
\hline El gran reto musical & $@$ GranRetoTVE & - & 4 & - \\
\hline Insuperables & @InsuperablesTVE & - & 2 & - \\
\hline Aquí la tierra & $@$ aquilatierratve & 4 & 14 & $00: 18$ \\
\hline Pueblo de Dios & $@$ PueblodeDiostve & - & - & - \\
\hline Maestros de la costura & @MaestrosCostura & 10 & 6 & $00: 40$ \\
\hline Mira quién baila & @Baila_TVE & - & 2 & - \\
\hline Atención, obras & @atencionobras & - & 4 & \\
\hline El cazador de cerebros & @cazadorcerebros & 1 & 8 & $01: 10$ \\
\hline El pueblo más divertido & @pueblodivertido & - & - & - \\
\hline Masterchef & $@$ masterchef & 6 & 4 & $00: 22$ \\
\hline Días de cine & @DiasDeCine & - & - & - \\
\hline Torres en la cocina & @ torrescocinatve & 20 & - & $01: 00$ \\
\hline
\end{tabular}

Tabla 3. Datos porcentuales y duración media del perfil Programas

En las cuentas correspondientes a los programas Aquí hay trabajo (búsqueda de empleo), Desaparecidos (búsqueda de personas desaparecidas), Pueblo de Dios (historias de humanidad), El pueblo más divertido (concurso) y Días de cine (actualidad cinematográfica) no se han encontrado documentos audiovisuales en el periodo de tiempo analizado. En el caso de Órbita Laika (programa dedicado a ciencia y humor) los videos carecen de audio y en su mayoría, se asemejan a gif animados.

En el perfil del programa musical Cachitos de hierro y cromo se han localizado 12 vídeos. De ellos, sólo 5 tuits son de la cuenta analizada y van acompañados de vídeo y su formato se basa en promos de festivales y cine que se podrán ver en la segunda cadena de TVE.

El programa Cámara abierta, dedicado al ámbito de la innovación y la cultura en la red, concentra la muestra en el mes de julio y finales de junio. Se han localizado un total de 16 videos, de los cuales 11 son tuits propios con documento audiovisual $(22 \%)$. De los formatos registrados (gráfico 4 ), avance de programa y noticias ocupan un mayor espacio con el $54,5 \%$ y $27,2 \%$ respectivamente.

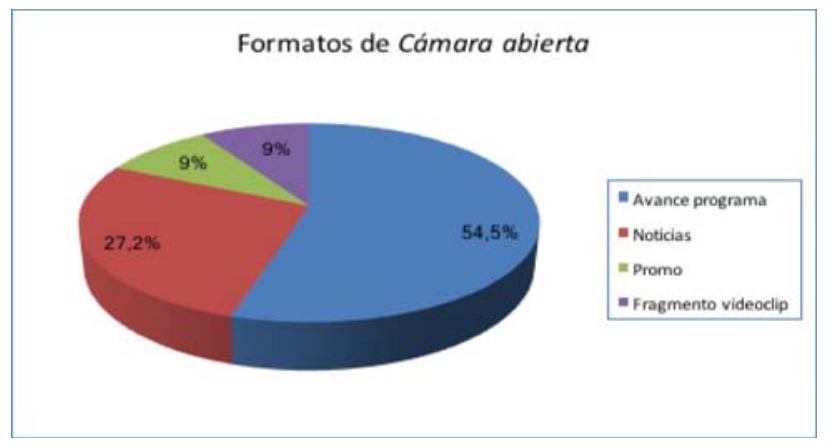

Gráfico 4. Promedio de vídeos por formatos de Cámara abierta (@camaraabierta) 
Al igual que en este caso, Hora Punta recoge la muestra durante los meses de junio y julio, coincidiendo con la despedida por vacaciones. Se ha localizado un total de 17 videos propios (34\%). El gráfico 5 representa los cinco formatos localizados destacando los fragmentos de entrevistas con casi el 53\%.

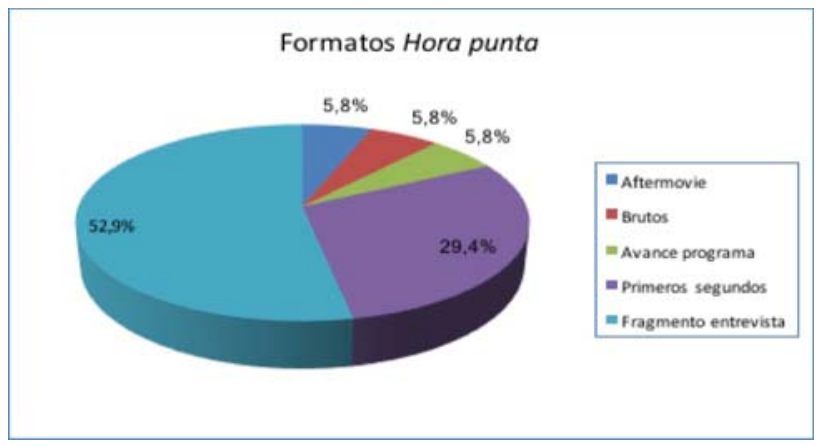

Gráfico 5. Promedio de vídeos por formatos de Hora punta (@HoraPuntaTVE)

Los documentos existentes en el perfil Trabajo temporal se remontan a marzo de 2017, fecha en la que se interrumpe la publicación de tuits. Con carácter retroactivo, de los últimos 50 tuits sólo se han registrado 3 tuits propios con video, lo que supone un $6 \%$. Similar al caso anterior se encuentra el perfil del talent show, El gran reto musical, cuya actividad se paraliza en marzo de 2017. Se han localizado únicamente 2 vídeos; uno de ellos retuiteado de la cuenta @playz con 20" de duración y el segundo de apenas 11 " pero carece de audio.

Los resultados alcanzados en Zoom Net, programa dedicado al terreno de las tecnologías y la cultura digital, abarcan algo más de un mes: del 15 de junio al 27 de julio. Se registran 7 videos como tuits propios, con una duración media de prácticamente un minuto. En relación con los dos formatos que se han hallado priman los avances de programa con un $85,7 \%$ frente al $14,2 \%$ de los fragmentos de programa.

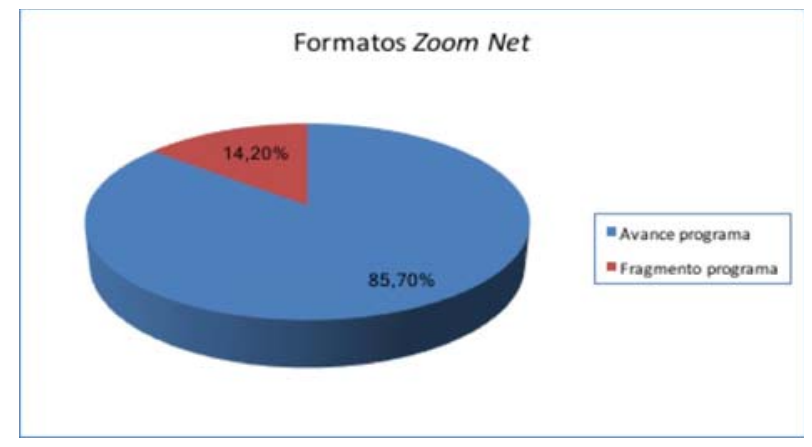

Gráfico 6. Promedio de vídeos por formatos de Zoom Net (@ZoomNet_tve)

Los programas Mira quien baila e Insuperables, cortan su actividad en el año 2015, arrojando como resultado un único retuit. Por su parte, aunque se haya actualizado este verano, el perfil Atención, obras, programa de ámbito cultural centrado en 
la música, las artes escénicas y plásticas, cuenta con 2 retuits procedentes de cuentas personales. También son pocos, sólo 2 tuits con video (4\%) y ambos con material bruto, lo que se ha localizado en la cuenta del programa Aquí la tierra, el cual ha mantenido su actividad en el mes de agosto. La cantidad de retuits difundidos es mayor; 7 vídeos, lo que supone un $14 \%$ del total localizado. En la misma línea se sitúa El cazador de cerebros con 4 retuits pertenecientes a cuentas personales y un único tuits del 31 de diciembre de 2017, donde el equipo felicita el año a los espectadores.

En Maestros de la costura, talent show cuya emisión comenzó en febrero de este año, se han localizado 8 vídeos de los cuales 5 son tuits propios. Ese $10 \%$ está concentrado en fragmentos del programa en el que se va mostrando a los concursantes y espectadores del programa la explicación del patrón al que se tienen que enfrentar los participantes. Respecto al concurso Masterchef se han registrado 3 tuits propios (6\%) con una media de $22^{\prime \prime}$. Se trata de 3 promos en las que se van presentando a los diferentes concursantes de la edición que en este mes de septiembre ha comenzado a emitirse.

Por último, dentro de este apartado dedicado a los programas, estaría el espacio de gastronomía titulado Torres en la cocina. Se han encontrado un total de 20 vídeos que corresponden con 20 tuits propios del programa. En relación con los formatos, estos se ejemplifican en la tipología que se refleja en el gráfico 7.

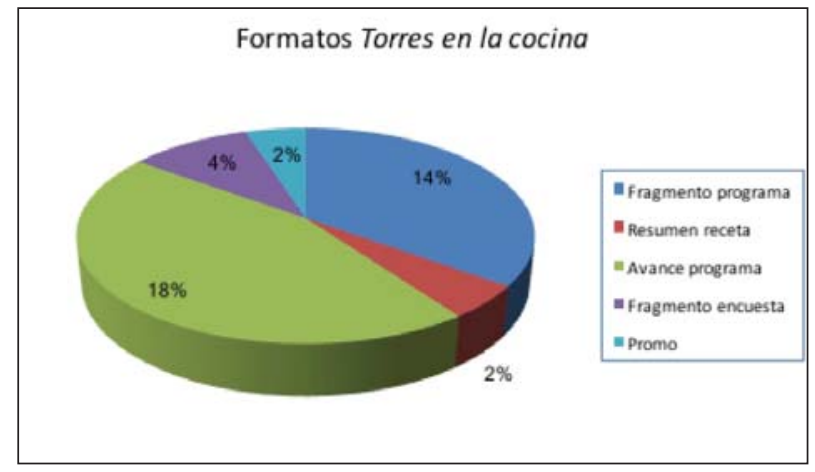

Gráfico 7. Promedio de vídeos por formatos de Torres en la cocina (@torrescocinatve)

\section{Corporativos}

A continuación, la tabla 4 muestra los resultados de los perfiles pertenecientes a la cadena o a los canales de la cadena.

\begin{tabular}{|l|l|l|l|l|}
\hline Perfil Informativo & Cuentas & $\begin{array}{l}\text { Tuits con vi- } \\
\text { deos (\%) }\end{array}$ & $\begin{array}{l}\text { Videos retui- } \\
\text { teados (\%) }\end{array}$ & $\begin{array}{l}\text { Duración media } \\
\text { (Tuits) }\end{array}$ \\
\hline TVE & @tve_tve & 8 & 18 & $01: 08$ \\
\hline La 1 & @La1_tve & 17,3 & 10,7 & $00: 39$ \\
\hline La 2 & @la2_tve & 21,3 & 7,3 & $00: 35$ \\
\hline Clan & @clan_tve & 6 & 0 & $00: 26$ \\
\hline 24 Horas & @24h_tve & 18 & 26 & $01: 15$ \\
\hline Eurovisión & @eurovision_tve & 14 & 8 & $00: 46$ \\
\hline
\end{tabular}




\begin{tabular}{|l|l|l|l|l|}
\hline El Tiempo & @eltiempo_tve & 31,3 & 8 & $01: 43$ \\
\hline Archivo RTVE & @ArchivoRTVE & 34,7 & 6 & $01: 00$ \\
\hline Playz & @playz & 43,3 & 3 & $00: 55$ \\
\hline RTVE & @ rtve & 2 & 16 & $01: 27$ \\
\hline Teledeporte & @ teledeporte & 0 & 5 & - \\
\hline
\end{tabular}

Tabla 4. Datos porcentuales y duración media del perfil Corporativos

Comenzamos con resultados del grupo "Corporativos" agrupando los perfiles generales de la cadena: TVE, RTVE, $L a 1$ y $L a 2$. Los dos más generales apenas publican tuits propios: $8 \%$ TVE y $2 \%$ RTVE. Vemos un mayor porcentaje de retuits de otros perfiles de la cadena y, en cambio, muy pocos tuits con vídeo de producción propia (un 2\% de RTVE frente al 16\% de retuits). Sí hay más actividad propia en los perfiles de las dos cadenas principales, $L a 1$ y $L a 2$, tal y como muestran los gráficos 8 y 9 respectivamente. En $L a 1$ se observa más variedad de formatos que en $L a 2$, donde la gran mayoría de vídeos son promos de espacios de la propia cadena.

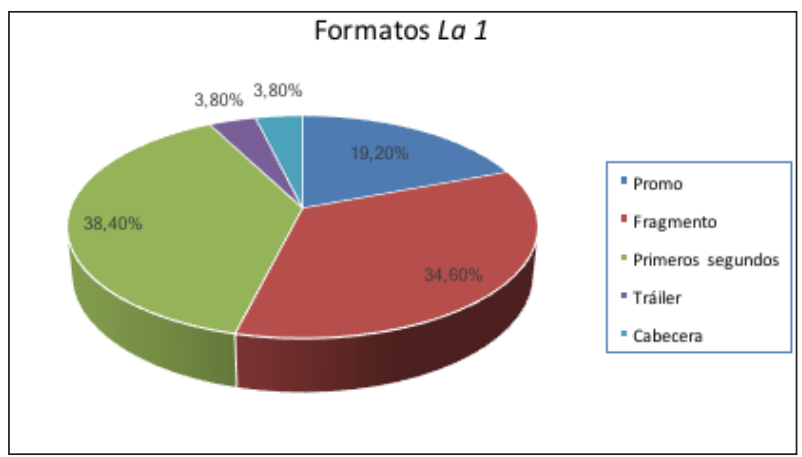

Gráfico 8. Promedio de vídeos por formatos de "La 1” (@La1_tve)

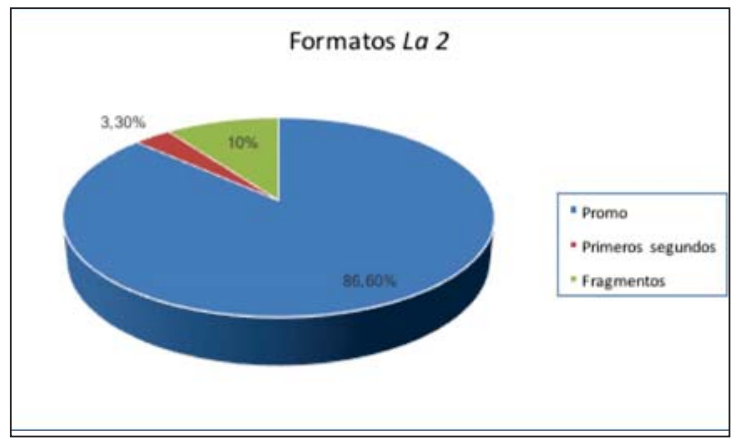

Gráfico 9. Promedio de vídeos por formatos de La 2 (@la2_tve) 
El perfil del canal 24 Horas publica un $18 \%$ de tuits propios con vídeo frente a un $26 \%$ de vídeos retuiteados. De ese $18 \%$ original (gráfico 10), la gran mayoría $(88,8 \%)$ son noticias.

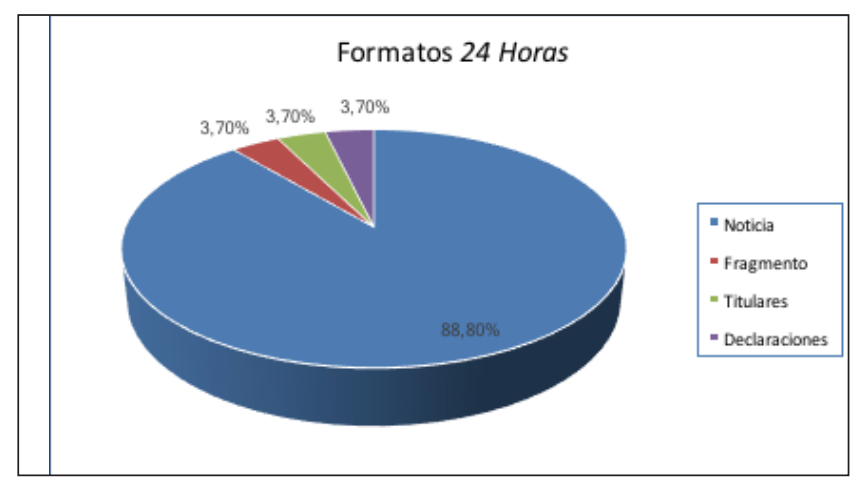

Gráfico 10. Promedio de vídeos por formatos de 24 Horas (@24h_tve)

El perfil de El Tiempo es uno de los que tiene formatos propios del canal, como se indicó anteriormente: en este caso "predicción" o "tiempo pasado". De un total de 150 tuits recogidos en la muestra, un $31,3 \%$ son tuits con vídeo propios, y un $8 \%$ retuits con vídeo. De ese $31,3 \%$ encontramos, como muestra el gráfico 11 , una amplia mayoría de predicciones $(95,7 \%)$ y tan solo un $4,3 \%$ de información sobre el tiempo ya pasado.

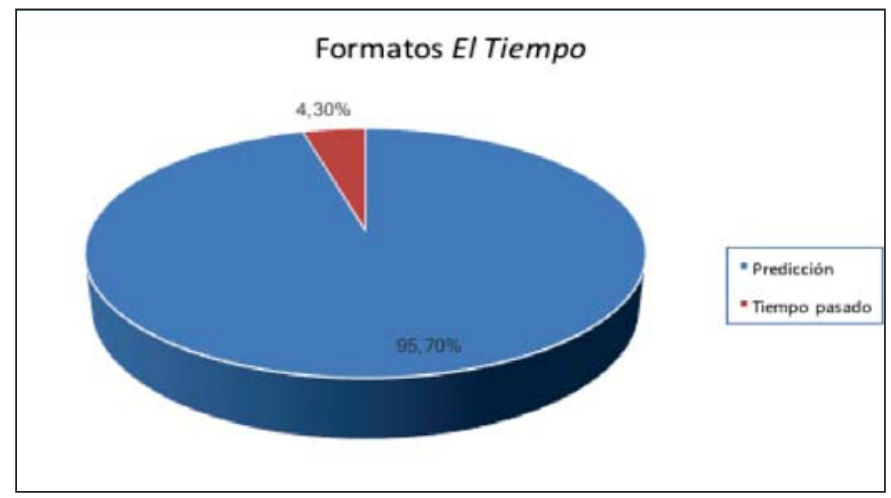

Gráfico 11. Promedio de vídeos por formatos de El tiempo (@eltiempo_tve)

Uno de los perfiles que más vídeos propios publica es Archivo RTVE, con un total de $34,7 \%$ de tuits con vídeos propios, y solo un $6 \%$ de vídeos retuiteados. En el gráfico 12 vemos la variedad de formatos publicados por esta cuenta: la mayoría son fragmentos de programas antiguos de la cadena (37\%), y el resto muestra variedad de formatos. 


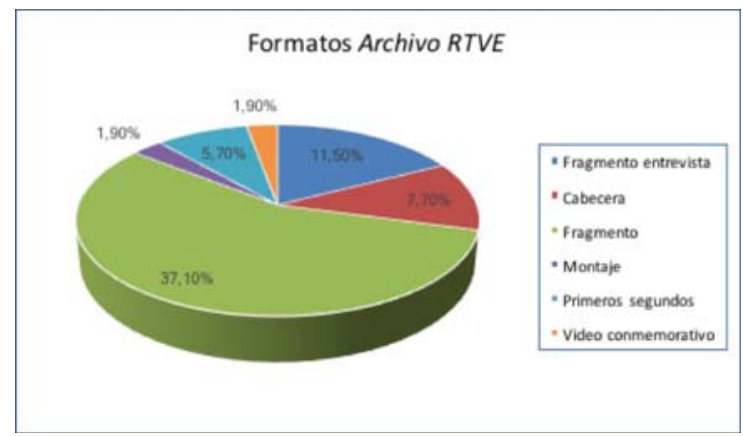

Gráfico 12. Promedio de vídeos por formatos de Archivo RTVE (@ArchivoRTVE)

El perfil que más vídeos publica del bloque "Corporativos" es Playz. Casi la mitad de la muestra (un 43,3\%) iban acompañados de vídeo. En cambio, hay muy pocos retuits con piezas audiovisuales: solo un 3\%. De ese 43,3\% encontramos una mayoría de fragmentos de entrevista $(38,4 \%)$, y bastante variedad de formatos, como se ve en el gráfico 13 .

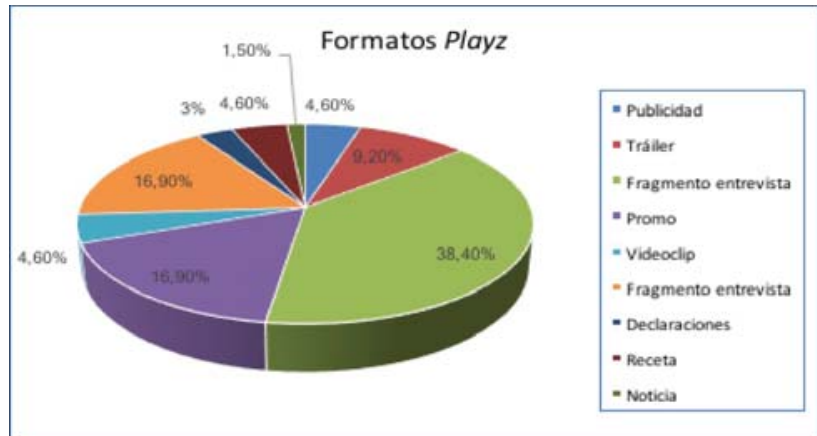

Gráfico 13. Promedio de vídeos por formatos de Playz (@playz)

\section{Series}

Finalizamos los resultados con datos del grupo "series", reflejados en la tabla 5.

\begin{tabular}{|l|l|l|l|l|}
\hline Perfil Informativo & Cuentas & $\begin{array}{l}\text { Tuits con } \\
\text { videos (\%) }\end{array}$ & $\begin{array}{l}\text { Videos retui- } \\
\text { teados (\%) }\end{array}$ & $\begin{array}{l}\text { Duración } \\
\text { media } \\
\text { (Tuits) }\end{array}$ \\
\hline Cuéntame cómo pasó & @ cuentametve & 14 & & $00: 32$ \\
\hline El ministerio del tiempo & @MdT_TVE & - & 2 & - \\
\hline Acacias 38 & @acacias38_tve & 54 & 3 & $00: 31$ \\
\hline El caso & @elcaso_tve & 4 & - & $00: 25$ \\
\hline Servir y proteger & @SyP_tve & 61,3 & - & $00: 54$ \\
\hline La otra mirada & @laotramiradatve & 22 & - & $00: 55$ \\
\hline
\end{tabular}

Tabla 5. Datos porcentuales y duración media del perfil Series 
Comenzamos con la serie más longeva del grupo, Cuéntame cómo pasó. Con un $14 \%$ de tuits con vídeo originales y ningún retuit, La mayoría de sus vídeos muestran el proceso de grabación, con un 57,1\% de "making of".

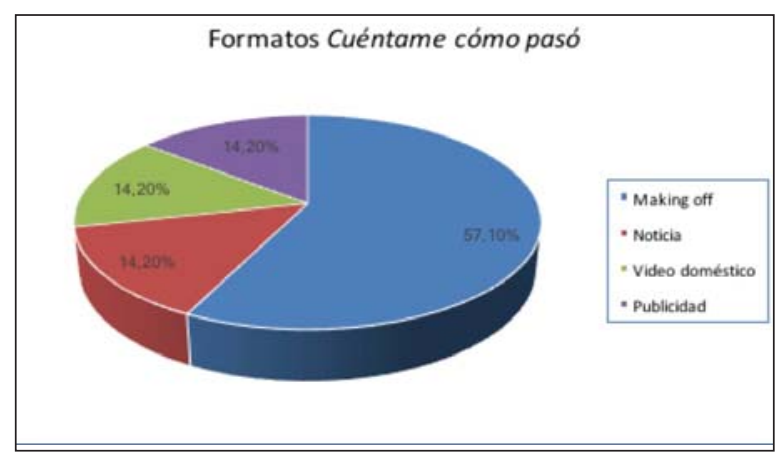

Gráfico 14. Promedio de vídeos por formatos de Cuéntame cómo pasó (@cuentametve)

Acacias 38, con un 54\% de tuits con vídeos, es uno de los perfiles que más vídeos propios publica en Twitter junto con Servir y proteger, que alcanza un $61,3 \%$. Como vemos en los gráficos 15 y 16, de ese abultado porcentaje, la inmensa mayoría (en los dos perfiles) son vídeos propios: un 85,1\% en Acacias 38 y un 91,3\% en Servir y proteger.

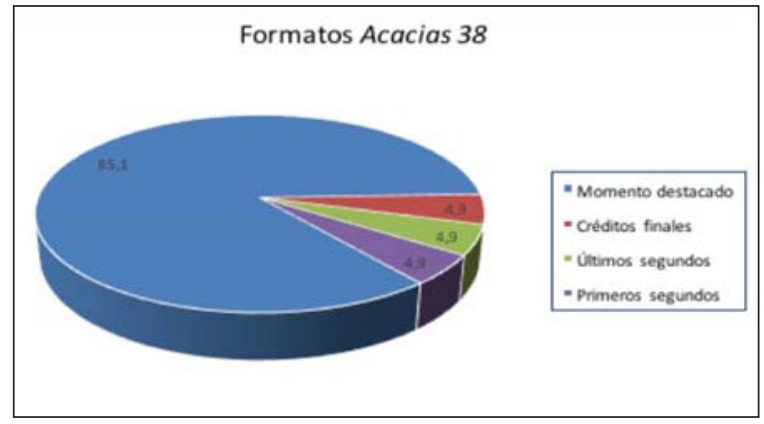

Gráfico 15. Promedio de vídeos por formatos de Acacias 38 (@acacias38_tve)

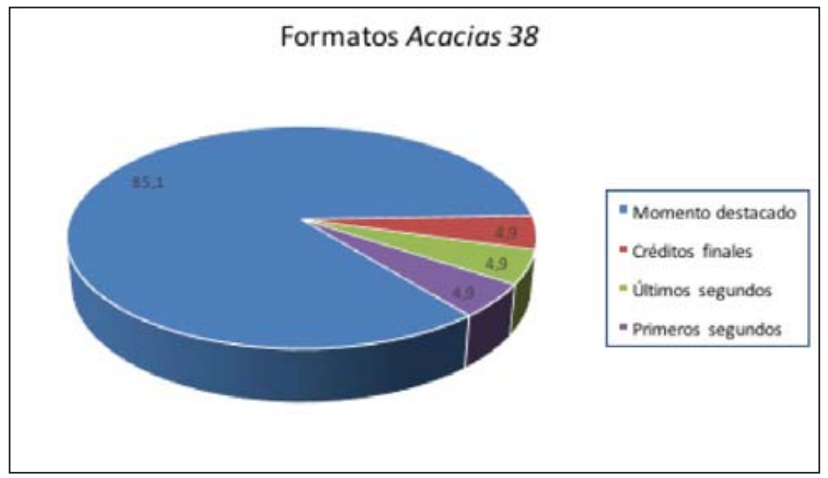

Gráfico 16. Promedio de vídeos por formatos de Servir y proteger (@SyP_tve) 


\section{Conclusiones}

Partiendo de los resultados obtenidos, se puede considerar que Twitter ha sobrepasado sus funciones iniciales de red social o microblogging para llegar a ser un garante de la conservación del patrimonio audiovisual de una determinada cadena y no un simple contenedor de nuevos formatos o fórmulas informativas. De nada servirían todos esos nuevos registros disponibles a través de esta red social si el usuario no pudiera disponer de ellos. Todo ello entronca con un peligro al que hay que hacer frente desde el punto de vista informativo y documental, originado por la inmediatez implícita en Twitter: la desinformación junto con la dificultad que conlleva el procesamiento de ingentes cantidades de información.

De la cadena estudiada se ha observado que en ocasiones su perfil oficial es redundante, dado que se limita a retuitear las publicaciones de las dos cadenas principales, $L a 1$ y $L a 2$, con pocas aportaciones originales.

Los perfiles oficiales de las series de televisión en activo publican tuits breves, de un minuto aproximadamente, y mantienen una actividad muy intensa durante la emisión del episodio. Sin embargo, cuando la serie deja de emitirse, pese a que el perfil siga activo y verificado, la actividad cesa casi totalmente, salvo algunas acciones más encaminadas a la publicidad de la serie y sus productos de venta al público. Los perfiles de algunas series de televisión podrían llegar a ser un sustituto de la propia serie. Con los vídeos "momentos destacados" puede estar al tanto de la trama sin necesidad de ver el episodio completo.

Como cabía esperar, las noticias, titulares y fragmentos de entrevistas son los formatos que mayor porcentaje obtienen en el grupo "Informativo" y este dato se ha observado tanto en los tuit como retuits. Inherente a la propia naturaleza de la red social analizada, en la mayoría de los casos, los fragmentos de entrevista permiten tener una idea general de lo más relevante señalado por el entrevistado en un espacio concreto. Por esa misma naturaleza intrínseca de Twitter, los fragmentos y avances de programas alcanzan una mayor presencia.

No solo las cuentas de Twitter publican tuits que aseguran la preservación del patrimonio audiovisual de la cadena, sino que son una fuente de nuevos materiales audiovisuales. Hemos visto ejemplos como los "aftermovie", o la categoría a la que hemos llamado "frase/instante". Los "aftermovie" son montajes con los momentos más destacados de un evento, serie, concurso o cualquier otro acontecimiento, que se edita con un montaje dinámico y una música atractiva, como resumen de lo que fue tal acontecimiento o serie. La categoría que hemos llamado "frase" o "instante" parece estar destinada a otro fin distinto que el de conservar el patrimonio audiovisual: tuitear solo una frase contundente, o unos segundos de una imágenes llamativas pueden estar destinadas a provocar que el usuario de las redes vuelva a publicarlas fuera de contexto, bien como "meme" (es famoso un fragmento de Leonardo di Caprio aplaudiendo), o bien para apoyar una opinión en un tuit sobre cualquier tema. Otro ejemplo puede ser la categoría "receta", en la que se explica la elaboración de un plato sencillo con un montaje ágil de un minuto.

Por último, se constata que Playz es el perfil que más vídeos publica en Twitter; sorprendentemente, más que la cuenta Archivo RTVE. Esto es debido, probablemente, a que el lenguaje que mejor entiende su público objetivo (jóvenes) es el lenguaje audiovisual. 


\section{Bibliografía}

Cerviño Queiroz, B. (2013). El uso de las redes sociales como fuentes de información para periodistas. TFM. Barcelona. Universidad Autónoma de Barcelona. Disponible en: https://www.recercat.cat/bitstream/handle/2072/216886/Versi\%C3\%B3n\%20digital\%20 del\%20trabajo.pdf

Edmondson, Ray (2018). Archivos audiovisuales: filosofía y principios. UNESCO. ISBN: 978-607-535-052-3 Rev.1. Disponible en: http://unesdoc.unesco.org/images/0026/002641/264105s.pdf

Egea Bas, S. (2016). Twitter, de red social a medio de comunicación: análisis e influencia en el ámbito empresarial Caso de estudio: Pullmantur e Iberia (2011-2014). Tesis doctoral. Madrid, Universidad Complutense de Madrid. Disponible en: https://eprints.ucm. es/42329/1/T38683.pdf

Fernández-Quijada, David; Fortino, Montse (2009). "Servicio público de televisión y patrimonio audiovisual: el proyecto VideoActive". El profesional de la información, 2009, 18/5, 545-551. Disponible en: https://recyt.fecyt.es/index.php/EPI/article/viewFile/38226/21580

Gallego, F. (2013). "Social TV Analytics: Nuevas métricas para una nueva forma de ver televisión”. Index.Comunicación, 2013, 3/1, 13-39. Disponible en: http://journals.sfu.ca/ indexcomunicacion/index.php/indexcomunicacion/article/view/49/56

García Estévez, Noelia (2018). La sociedad interconectada y la profesionalización comunicativa. Sevilla, Universidad de Sevilla, ISBN: 978-84-09-01465-1. Disponible en: https:// idus.us.es/xmlui/bitstream/handle/11441/75748/lasociedadinterconectada.pdf?sequence $=1 \&$ isAllowed $=y$

González-Molina, S., Ramos del Cano, F. (2014). "Las redes sociales en el ámbito periodístico: ¿cómo usan los medios europeos de referencia sus perfiles en Twitter y Facebook?”. Comunicación y Hombre, 2014, 10, 37- 52. Disponible en: https://core.ac.uk/download/ pdf/47059938.pdf

Hidalgo, Paloma (2013). Patrimonio audiovisual en televisión. En Marcos Recio, Juan Carlos (Coord.): Gestión del patrimonio audiovisual en medios de comunicación. Madrid, Editorial Síntesis, pp. 53-82. ISBN: 9788499589794

Hidalgo, Paloma (2017). Preservación del patrimonio audiovisual de televisión El archivo de Televisión Española (TVE): de los orígenes a la digitalización. Tesis Doctoral. Madrid, Universidad Complutense de Madrid. Disponible en: https://eprints.ucm.es/41938/1/ T38624.pdf

Jenkins, H. (2008). Convergence Culture: la cultura de la convergencia de los medios de comunicación. Barcelona, Paidós, ISBN 978-84-493-2153-5. Disponible en: https://stbngtrrz.files.wordpress.com/2012/10/jenkins-henry-convergence-culture.pdf

López Meri, Amparo (2015). "El impacto de Twitter en el periodismo: un estado de la cuestión”. Revista de la Asociación española de investigación de la comunicación, 2015, 2/4, 34-41. Disponible en: http://repositori.uji.es/xmlui/bitstream/handle/10234/165677/Lopez_2015_Impacto.pdf? sequence $=1 \&$ is Allowed $=y$

Martínez Gutiérrez, Fátima (2014). Los nuevos medios y el periodismo de medios sociales. Tesis doctoral. Madrid, Universidad Complutense de Madrid. Disponible en: https:// eprints.ucm.es/24592/1/T35106.pdf

Noguera Vivo, José Manuel (2011). Redes y periodismo. En Noguera Vivo, J.M., Martínez Polo, J, Grandío Pérez, Ma del M.: Redes sociales para estudiantes de Comunica- 
ción: 50 ideas para comprender el escenario online. Barcelona, OUC, pp. 57-120. ISBN: 9788497889759

Pérez-Sánchez, J. (2018). Los informativos del canal autonómico CMMedia en Redes Sociales. En Segarra-Saavedra, J; Hidalgo-Marí, T; Rodríguez-Ferrándiz, R (Coords.): Actas de las Jornadas Científicas Internacionales sobre análisis del discurso en un entorno transmedia, Alicante, Universidad de Alicante, pp. 103-113. ISBN 978-84-617-9386-0. Disponible en: http://www.doi.org/10.14198/MEDCOM/2017/11_cmd

Salaverría, R., García Avilés, J. A. (2008). "La convergencia tecnológica en los medios de comunicación: retos para el periodismo". Tripodos, 2008, 23, 31-47. Disponible en: https://www.raco.cat/index.php/Tripodos/article/viewFile/118910/154114 pp. 31-47.p. 32

Vinader, R.; Cuadra Colmenares, E. de la (2012) "Televisión 2.0: las estrategias comunicativas en la Web social”. Estudios sobre el Mensaje Periodístico, 2012, 18, 909-918. Disponible en: http://dx.doi.org/10.5209/rev_ESMP.2012.v18.40969 